\title{
Secondhand effects of student alcohol use reported by neighbors of colleges: the role of alcohol outlets
}

\author{
Henry Wechsler ${ }^{\mathrm{a}, *}$, Jae Eun Lee ${ }^{\mathrm{a}}$, John Hall ${ }^{\mathrm{b}}$, Alexander C. Wagenaar ${ }^{\mathrm{c}}$, Hang Lee ${ }^{\mathrm{d}}$ \\ ${ }^{a}$ Harvard School of Public Health, Department of Health and Social Behavior, 677 Huntington Avenue, Boston, MA 02115, USA \\ ${ }^{\mathrm{b}}$ Mathematica Policy Research, 600 Alexander Park, Princeton, NJ 08543, USA \\ ${ }^{\mathrm{c}}$ Department of Epidemiology, School of Public Health, University of Minnesota, 1300 South 2nd Street, Suite 300, Minneapolis, \\ MN 55454-1015 USA \\ ${ }^{\mathrm{d}}$ Center for Vaccine Research \& Department of Pediatrics, UCLA School of Medicine, 1124 West Carson Street, \\ Research and Education Building E-6, Torrance, CA 90502, USA
}

\begin{abstract}
This is a study of the secondhand effects of student alcohol use experienced by residents of neighborhoods near college campuses. We examined the relationship of a college's level of binge drinking and the number of alcohol outlets in the immediate area, to lowered quality of neighborhood life through such secondhand effects. Adults from 4661 households in the United States were interviewed through a stratified list-assisted random digit dialing telephone survey. The interview schedule included questions about residents' experiences of secondhand effects of alcohol use such as noise, vandalism or public disturbances. Reports about the quality of neighborhood life provided by respondents residing near colleges were compared with those of respondents who did not live near colleges; and reports of neighbors of colleges with high rates of binge drinking were compared with those of neighbors of colleges with lower rates. The presence of alcohol outlets in these areas was also compared. Residents near colleges and particularly near colleges with heavy episodic drinking reported the presence of more alcohol outlets within a mile. Those neighborhoods were characterized by lower socioeconomic status. Neighbors living near college campuses were more likely to report a lowered quality of neighborhood life through such secondhand effects of heavy alcohol use as noise and disturbances, vandalism, drunkenness, vomiting and urination. A path analysis indicated that the number of nearby alcohol outlets was an important factor mediating the relationship between colleges, especially those with high rates of binge drinking, and such secondhand effects. The results suggest that neighborhood disruptions around colleges due to heavy alcohol use may be reduced by limiting the presence of alcohol outlets in those areas, and the marketing practices that this engenders. (C) 2002 Elsevier Science Ltd. All rights reserved.
\end{abstract}

Keywords: Neighborhood; College students; Alcohol use; Environment; Alcohol-related disruption; Alcohol outlet density; Socioeconomic status; USA

\section{Introduction}

In 1993, the Harvard School of Public Health College Alcohol Study (CAS) found that two in five US college students were binge drinkers (Wechsler, Davenport, Dowdall, Moeykens, \& Castillo, 1994) and this rate

\footnotetext{
*Corresponding author. Tel.: +1-617-432-1137; fax: +1617-432-3223.

E-mail address: hwechsle@hsph.harvard.edu (H. Wechsler).
}

remained constant in two follow up surveys (1997 and 1999) over a 6-year period (Wechsler, Dowdall, Maenner, Gledhill-Hoyt, \& Lee, 1998, 2000a). Among the problems associated with these high levels of alcohol use are what we have termed "secondhand" effects. Wechsler, Moeykens, Davenport, Castillo, and Hansen (1995b) found that non-binge drinking students residing on campuses where more than half of students were binge drinkers were twice as likely to experience secondhand effects than non-binge drinkers living on campuses with 
fewer binge drinkers. These secondhand effects include having sleep or study interrupted, having to take care of a drunken student, being insulted or assaulted, being the victim of unwanted sexual advances, or having personal property vandalized.

Heavy alcohol consumption by college students and others may be encouraged by a "wet" environment, that is, an environment in which alcohol is prominent and easily accessible (Edwards et al., 1995). Physical, social, and economic availability of alcohol is associated with alcohol consumption among the general population (Parker, Wolz, \& Harford, 1978; Rush, Steinberg, \& Brook, 1986; Abbey, Scott, Olinsky, Quinn, \& Andreski, 1990; Abbey, Scott, \& Smith, 1993; Gruenewald, Madden, \& Janes, 1992; Gruenewald, Miller, \& Treno, 1993) and among young adolescents and older teenagers (O'Malley \& Wagenaar, 1991; Wagenaar, 1993; Wagenaar et al., 1996; Jones-Webb et al., 1997). High density of alcohol outlets has been found to be associated with higher rates of alcohol-related health and social problems such as homicide (Scribner, Cohen, Kaplan, \& Allen, 1999), assaultive violence (Alaniz, Parker, Gallegos, \& Cartmill, 1996; Alaniz, Cartmill, \& Parker, 1998; Gorman, Speer, Labouvie, \& Subaiya, 1998a; Scribner, MacKinnon, \& Dweyer, 1995; Speer, Labouvie, \& Ontkush, 1998), domestic violence (Gorman, Labouvie, Speer, \& Subaiya, 1998b), traffic safety outcomes (Rabow \& Watts, 1982; Jewell \& Brown, 1995; Scribner et al., 1994), and mortality, morbidity and economic costs (Tatlow, Clapp, \& Hohman, 2000; Mann, Smart, Anglin, \& Adlaf, 1991; Rabow \& Watts, 1982; Scribner, Cohen, \& Farley, 1998; Gorsky, Schwartz, \& Dennis, 1988; Smart, Mann, \& Suurvali, 1998). Alcohol outlets and advertising appear to be over-concentrated in ethnic minority communities (Alaniz, 2000; Hackbarth, Silvestri, \& Cosper, 1995; Altman, Schooler, \& Basil, 1991; LaVeist and Wallace, 2000), implying that it is necessary to understand the sociodemographic and economic background of a community in coping with drinking problems.

As Gruenewald and others (1995) have pointed out, most of these studies find relationships between outlets, demographics, and drinking patterns, but most do not provide a theoretical basis for understanding such interrelations. One such theoretical approach receiving increased attention recently is the "routine activities" theory (Fox \& Sobol, 2000). Most commonly applied to crime victimization, routine activity theorists find that more frequent "going out" increases one's risk of victimization (Mustaine \& Tewksbury, 1998). In the context of college drinking, one might argue that high rates of heavy drinking and alcohol-related problems among college students are "simply" the result of their frequent and routine activity of going out, particularly to bars and nightclubs. Thus, just as time spent walking the street increases exposure to risk of (one type of) assault, time spent in bars increases exposure to the risk of experiencing secondhand effects of heavy drinking. The point remains, however, that a high density of bars and clubs around campuses may encourage heavier drinking among students.

Alcohol use rates and related problems have been reduced by strategies to restrict alcohol availability. Coate and Grossman (1988) reported that as alcohol excise taxes increased, youth drinking rates and deaths resulting from motor vehicle accidents significantly decreased. O'Malley and Wagenaar (1991) found that as states increased minimum drinking age laws, alcohol use and problems associated with it significantly decreased. Chiu, Perez, and Parker (1997) reported that an alcohol ban, its lifting, and its re-imposition had statistically significant effects on the number of alcoholrelated outpatient visits in a geographically isolated community. Restrictive alcohol control policies significantly affected injury death rates in a population with extremely high injury mortality (Berman, Hull, \& May, 2000).

Colleges with large numbers of binge drinkers are characterized by greater visibility and availability of alcohol in their environment. College students' binge drinking is associated with the degree of ease of access to alcohol (Wechsler, Kuo, Lee, \& Dowdall, 2000b), location of a bar within a mile from campus (Wechsler et al., 1994), price (Chaloupka, Grossman, \& Saffer, 1998; Wechsler et al., 2000b), and state alcohol control policies (Chaloupka et al., 1998).

Clearly, drinking levels and rates of alcohol-related problems are associated with state and local policies as well as alcohol availability, price, and marketing practices. For many dimensions of the policy and marketing environment (e.g., alcohol taxes, drinking age), we know that the causal influence runs from policy to drinking. For others (e.g., outlet density), the causal influences may be reciprocal, with the environment encouraging drinking, and heavy drinking encouraging deterioration of the community environment. The current study examines the interrelationships between a community environment that encourages drinking and a concentration of heavy drinkers (on college campuses) that shape the community environment. Specifically, we used surveys of community residents around colleges, along with surveys of student behavior on those campuses to answer the following questions:

- Are there more alcohol outlets in neighborhoods near colleges than in similar neighborhoods which are not near colleges?

- Do residents living in communities near a college experience more secondhand effects of alcohol use than residents of similar areas not near a college?

- Are the increased secondhand effects related to more alcohol outlets near a college? 
- Do residents of areas near colleges with high levels of binge drinking experience more secondhand effects than residents of areas near colleges with low levels of binge drinking?

\section{Methods}

\section{Study procedure}

We conducted a telephone survey of adult residents of the contiguous United States plus the District of Columbia using a stratified list-assisted random digit dialing (RDD) sample purchased from Genesys Sampling Systems. ${ }^{1}$ The list-assisted method used covers an estimated $96.5 \%$ of all households with telephones (Brick, Waksberg, \& Starer, 1995). Actual coverage may be higher because the sample was selected at multiple points in time, so some households excluded early in the survey could have been included later on. Brick et al. (1995) concluded that list-assisted RDD sampling is "efficient and ... not subject to important coverage bias".

The survey was conducted by Mathemetica Policy Research of Princeton, NJ. The interview schedule included questions about residents' experiences of secondhand effects of heavy alcohol use such as noise, vandalism or public disturbances. Questions were patterned after those included in the Harvard School of Public Health College Alcohol Study student questionnaire (Wechsler, Dowdall, Davenport, \& Castillo, 1995a; Wechsler, Kelly, Weitzman, Giovanni, \& Seibring, 2000a). Respondents were also asked about their views on alcohol control policies, as well as personal background characteristics. The schedule was pre-tested on a small sample of respondents residing near colleges that were not part of the sampling frame. Minor revisions were done as a result of the pretest.

Survey interviews were conducted between March and August 1999. Up to 15 calls were attempted to obtain a completed interview for each sampled telephone number. English-speaking adults (age 18 and above) living in a household setting who were not full-time college students were eligible for the survey. In households with more than one eligible adult, one was randomly selected for the interview. Interviews were conducted by trained interviewers using conventional Computer Assisted Telephone Interviewing (CATI) methods.

A total of 9248 telephone numbers were called, with 4661 households identified. Of these, 2621 were study eligible and 2300 were successfully interviewed, yielding a completion rate of $86 \%$ and an estimated overall response rate of $50 \%$ using methods recommended by

\footnotetext{
${ }^{1}$ List assisted RDD sampling methods are described in Lepkowski (1988).
}

the Council of American Survey Research organizations (CASRO; Frankel, 1983). Despite the level of response, a comparison of selected demographic characteristics of the respondents with US census data indicated no significant differences, providing no strong evidence of selection bias on the basis of these variables.

\section{Sampling design}

We defined 7 strata for sample selection. Strata 1-4 included areas near high and low binge schools. A high binge school is one of the 30 schools with the highest prevalence of binge drinking among the 116 colleges participating in the 1997 Harvard School of Public Health College Alcohol Study (CAS). Similarly, a low binge school is one of the 30 schools that were lowest in the prevalence of binge drinking (Wechsler et al., 1998). The high binge areas include strata 1 (published numbers) and 2 (unpublished). The low binge areas are covered by strata 3 (published) and 4 (unpublished). More precisely, strata 1 and 2 included telephone numbers associated with census tracts that were estimated to be within a 1 mile radius of colleges that had been classified as high binge drinking schools. Strata 3 and 4 were similarly near colleges that had been classified as low binge drinking schools. Published and unpublished refer to whether a household's telephone number appeared in the telephone directory. Published numbers were assigned to stratum 1 or 3 based on their street addresses. Unpublished numbers were assigned to stratum 2 or 4 if they belonged to a telephone exchange where at least $30 \%$ of the published numbers were assigned to stratum 1 or 3 , respectively.

Strata 5 and 6 included households in counties that have colleges on the sample frame used in selecting the sample for the earlier student survey. Stratum 7 is the balance of the US. More specifically, stratum 5 included other counties with colleges provided the county had a large enough population to be selected with certainty when using probability proportional to size (PPS) methods. Stratum 6 included any other counties with one or more colleges on the sample frame. Stratum 7 comprised counties with no college on frame.

Telephone numbers in strata 1-4 also could have been sampled in either stratum 5 or 6 . These multiple chances of selection were accounted for in sample weighting. The sample is a multistage design. Within strata $1,2,3$, and 4 the primary sampling unit (PSU) is the college and the surrounding area. For stratum 6 the PSU is the county. In each case the secondary sampling unit is the household. The samples of households in strata 5 and 7 are not likely to be clustered.

Data were weighted to reflect differences in probability of selection and response rates across strata. Other components of the weights included adjustments for multiple telephone lines and for interruptions in 
telephone service, ${ }^{2}$ and post-stratification adjustments to national estimates of the population distribution by sex, age, race and home ownership. ${ }^{3}$ All analyses were conducted using weighted data.

\section{Measures}

Almost all of the measures in the study were obtained from responses to the completed interviews. Respondents were asked if they have seen or witnessed negative consequences of others' drinking (litter, noise or disturbance, vandalism, people who are drunk, fighting or assault to others, vomit or urination, and automobile accidents) one or more times in their neighborhood in the past year (secondhand effects). The number of neighbors experiencing four or more of these secondhand effects was examined. The secondhand effects were broken down into the incidents attributed to college students by asking if the college students were primarily responsible for the incident.

Community problems were measured by asking respondents if they thought neighborhood concerns and issues were a major problem or a problem in their neighborhood. Neighborhood concerns and issues included homelessness, crime, public drunkenness, drug use, vandalism, drunk driving, underage drinking, and loitering.

Respondents were asked to estimate the distance of the nearest college from their home: "How many miles from your home is the closest college or university (Please exclude community college in your answer)?" They were also asked to estimate how many alcohol outlets (on-premise and off-premise, separately) were located within 1 mile of their home.

In addition to survey data, we also used some variables from census data. Of the community background variables, estimates of income, racial composition, home ownership and age distribution were estimates at the telephone exchange level provided by Genesys Sampling Systems (Marketing Systems Group) or the US Census Bureau.

\footnotetext{
${ }^{2}$ Adjustments for interruption in telephone service allow the survey to compensate for the omission of non-telephone households. Very few households without telephone service on a given day never have telephone service. Most fall into what Keeter (1995) calls the "transient" category-having service some times and being without at others. By using a weight adjustment factor that is proportional to the number of months without telephone service, the transient telephone household population can be appropriately represented in sample estimates.

${ }^{3}$ Adjustments for home ownership were based on estimates provided by the sample vendor, Genesys Sampling Systems (Marketing Systems Group). Adjustments for age, race and sex were based on Census Bureau projections (Bureau of the Census, 2000).
}

Analysis

SUDAAN V. 7.5 (Shah, Barnwell, \& Bieler, 1997) was used for all Chi-square tests and multiple logistic regression analyses; SUDAAN employs a Taylor series linearization to approximate correct standard errors for sample estimates given the multistage sampling design of the survey and the effects of sample weighting. $2 \times 2$ Chisquare tests were used to examine the difference in socioeconomic backgrounds between communities defined by the distance (within and farther than 1 mile) from the closest college. Multiple logistic regressions were conducted to test if reported secondhand effects of drinking attributable to college students differed among residents of high and low heavy-episodic drinking school areas, and whether secondhand effects varied depending on the distance from the closest college. The logistic regressions controlled for socioeconomic background variables estimated at the telephone exchange level (racial composition, \% income $0-10 \mathrm{k}, \%$ owner occupied, $\%$ age $18-24$, and rural/urban).

We used structural equation models to examine how the distance from the closest college or the college binge drinking rate is related to numbers of alcohol outlets and the number of secondhand effects (controlling community's socioeconomic characteristics). We created an index of socioeconomic status reflecting race, income, home ownership, and population age distribution to simplify the model and avoid potential multicollinearity. When we conducted the path analysis, we assumed a unidirectional causal relationship between alcohol outlets and the environment even though there was the possibility of a bi-directional relationship between the two. Since our major concern through the path model was to determine the mediating role of alcohol outlets between college binge drinking and secondhand effects, we used a recursive rather than non-recursive model. The initial path model was based on our hypotheses. Fit of the model was evaluated by comparative fit index (CFI), Bentler and Bonett's (1980) non-normed fit index (NNFI), Bentler and Bonett's (1980) normed fit index (NFI), and the Chi-square goodness of fit. The statistical viability of the restrictions in the model was determined by Lagrange Multiplier test. The SAS CALIS procedure was used for structural equation modeling (Hatcher, 1994).

\section{Results}

\section{Community Background}

Income was significantly lower among respondents living within a mile than those living more than 1 mile from a college (Table 1). More African Americans, fewer whites, and, as expected, more young people aged 18-24 
Table 1

Socioeconomic characteristics of community by distance from college

\begin{tabular}{|c|c|c|c|c|}
\hline & \multicolumn{3}{|c|}{ Prevalence in $(\%)$} & \multirow[t]{2}{*}{ Chi-square $p$-value } \\
\hline & Total & $\begin{array}{l}\text { More than } \\
1 \text { mile }^{\mathrm{a}}(n=1692)\end{array}$ & $\begin{array}{l}\text { Within a mile }{ }^{\mathrm{a}} \\
(n=526)\end{array}$ & \\
\hline \multicolumn{5}{|c|}{$\begin{array}{l}\text { More than } 10 \% \text { of households have annual income less } \\
\text { than } \$ 10,000\end{array}$} \\
\hline Yes & 56.2 & 53.8 & 72.7 & 0.0005 \\
\hline No & 43.8 & 46.2 & 27.3 & \\
\hline \multicolumn{5}{|c|}{$\begin{array}{l}\text { More than } 12 \% \text { of individuals are African American } \\
\text { (non-Hispanic) }\end{array}$} \\
\hline Yes & 31.0 & 28.8 & 46.6 & 0.0028 \\
\hline No & 69.0 & 71.2 & 53.4 & \\
\hline \multicolumn{5}{|c|}{ More than $11 \%$ of individuals are Hispanic } \\
\hline Yes & 28.4 & 27.7 & 33.1 & 0.3095 \\
\hline No & 71.6 & 72.3 & 66.9 & \\
\hline \multicolumn{5}{|c|}{$\begin{array}{l}\text { More than } 71 \% \text { of individuals are White } \\
\text { (non-Hispanic) }\end{array}$} \\
\hline Yes & 61.8 & 64.3 & 43.9 & 0.0009 \\
\hline No & 38.2 & 35.7 & 56.1 & \\
\hline \multicolumn{5}{|c|}{$\begin{array}{l}\text { More than } 50 \% \text { of housing units are owner } \\
\text { occupied }\end{array}$} \\
\hline Yes & 84.9 & 87.7 & 65.4 & 0.0001 \\
\hline No & 15.1 & 12.3 & 34.6 & \\
\hline \multicolumn{5}{|c|}{ More than $10 \%$ of individuals are age $18-24$} \\
\hline Yes & 20.9 & 17.4 & 38.8 & $<0.0001$ \\
\hline No & 79.1 & 82.6 & 61.2 & \\
\hline
\end{tabular}

${ }^{\text {a }}$ Respondent's estimate of distance of home from college. $n=$ valid sample size.

lived within a mile from the college. Areas within a mile of a college had a lower prevalence of homeowners.

On-premise (bars/nightclubs) and off-premise (liquor stores) alcohol outlets were more often located within a mile from a college. Ninety-two percent of residents living within a mile from the closest college reported one or more alcohol outlets within a mile from their house compared to $75 \%$ of those who lived more than 1 mile away. After controlling for income, race, urbanism, and home ownership, respondents who lived within a mile from the nearest college were significantly more likely to report the presence of alcohol outlets nearby (adjusted $\mathrm{OR}=2.83 ; 95 \%$ CI: $1.47-5.47 ; p<0.001$; Table 2 ).

Community problems reported by respondents are presented in Table 3. Community problems reported most frequently were underage drinking $(60.8 \%)$, crime $(55.6 \%)$, vandalism $(52.3 \%)$, and drunk driving $(47.9 \%)$. Neighbors who lived within a mile from a college more often reported homelessness, crime, public drunkenness, drug use, underage drinking, and loitering than those living one or more miles from a college (Table 3).

\section{Distance from college and secondhand effects}

Respondents who lived within 1 mile from a college were significantly more likely to report noise and disturbances, vandalism, drunkenness, and vomit and urination than those living more than a mile from the school. They were significantly more likely to report four or more such effects (Table 4).

College students were not viewed as primarily responsible for most of these secondhand effects. Only about one-fourteenth of the respondents viewed college students to be responsible for vomit/urination $(7.8 \%)$, noise/disturbance $(6.9 \%)$, fighting/assault $(6.3 \%)$, and litter $(6.1 \%)$. College students were more often viewed to be responsible for litter, noise/disturbance, vandalism, and drunkenness by respondents living within 1 mile from a college, than by those living more than a mile from the school. One in five $(19.5 \%)$ respondents who lived within a mile from a college viewed college students to be responsible for at least one such effect, while one in twelve $(8.3 \%)$ living more than a mile away did. Those who lived within a mile were significantly more likely to report at least one of these effects.

Secondhand effects in low and high binge drinking college sites

While more respondents in high binge drinking school areas than in low binge drinking areas reported the presence of alcohol outlets within a mile of their homes 
Table 2

Presence of alcohol outlets by distance of respondent's home from college

\begin{tabular}{|c|c|c|c|c|}
\hline \multirow[b]{3}{*}{ Presence of bar/nightclub ${ }^{c}$} & \multirow{3}{*}{$\begin{array}{l}\text { More than } 1 \text { mile }^{\mathrm{a}}(n=1692) \\
(\%) \\
49.8\end{array}$} & \multicolumn{3}{|c|}{ Within a mile ${ }^{\mathrm{a}}(n=526)$} \\
\hline & & \multirow{2}{*}{$\frac{(\%)}{73.9}$} & \multicolumn{2}{|c|}{ Adjusted ORs $(95 \% \mathrm{CI})^{\mathrm{b}}$} \\
\hline & & & 2.17 & $(1.32-3.57)^{* * *}$ \\
\hline Presence of liquor store & 52.4 & 77.3 & 2.33 & $(1.32-4.17)^{* * *}$ \\
\hline Presence of other store that sells alcohol & 63.9 & 74.2 & 1.20 & $(0.75-1.92)$ \\
\hline Presence of any one of above alcohol outlets & 74.9 & 92.1 & 2.83 & $(1.47-5.47)^{* * *}$ \\
\hline
\end{tabular}

${ }^{a}$ Respondent's estimate of distance of home from closest college.

${ }^{\mathrm{b}} \mathrm{ORs}$ are adjusted for $\%$ income, $\%$ race, rural $/$ urban and $\%$ owner occupied. OR $=$ odds ratio. $95 \% \mathrm{CI}=95 \%$ confidence interval.

${ }^{\mathrm{c}}$ One or more self-reported alcohol outlets within 1 mile from house.

$* * * p<0.001 ; n=$ valid sample size.

Table 3

Reported community problems by distance of respondent's home from college

\begin{tabular}{|c|c|c|c|c|}
\hline & \multirow{2}{*}{$\begin{array}{l}\text { More than } 1 \text { mile }^{\mathrm{a}}(n=1692) \\
(\%)\end{array}$} & \multicolumn{3}{|c|}{ Within a mile ${ }^{\mathrm{a}}(n=526)$} \\
\hline & & $(\%)$ & Adju & $95 \% \mathrm{CI})^{\mathrm{b}}$ \\
\hline \multicolumn{5}{|l|}{ Community problems ${ }^{\mathrm{c}}$} \\
\hline Homelessness & 19.1 & 35.1 & 1.82 & $(1.11-3.03)^{*}$ \\
\hline Crime & 53.7 & 68.4 & 1.75 & $(1.12-2.78)^{* *}$ \\
\hline Public Drunkenness & 30.3 & 43.1 & 1.61 & $(1.01-2.56)^{*}$ \\
\hline Drug use & 44.7 & 58.8 & 1.67 & $(1.04-2.70)^{*}$ \\
\hline Vandalism & 51.4 & 58.5 & 1.33 & $(0.87-2.04)$ \\
\hline Drunk driving & 48.0 & 47.2 & 1.09 & $(0.72-1.64)$ \\
\hline Underage drinking & 59.5 & 69.9 & 1.64 & $(1.05-2.50)^{*}$ \\
\hline Loitering & 34.6 & 54.1 & 1.92 & $(1.23-2.94)^{* * *}$ \\
\hline Four or more problems reported & 44.0 & 59.7 & 1.89 & $(1.22-2.94)^{* * *}$ \\
\hline
\end{tabular}

${ }^{a}$ Respondent's estimate of distance of home from closest college.

${ }^{\mathrm{b}}$ ORs are adjusted for $\%$ income, $\%$ race, $\%$ age $18-24$, rural/urban, and $\%$ owner occupied. OR $=$ odds ratio. $95 \% \mathrm{CI}=95 \%$ confidence interval.

$\mathrm{c}_{\%}$ reporting this as a problem.

$* p<0.05 ; * * p<0.01 ; * * * p<0.001 ; n=$ valid sample size.

$(90.3 \%$ vs. $82.1 \%$, adjusted $\mathrm{OR}=2.33 ; 95 \% \mathrm{CI}: 1.45$ $3.70 ; p<0.001)$, no significant difference in socioeconomic status was found between the two school areas.

Respondents who lived in high-binge school areas more often reported litter and noise/disturbance by college students than those in low-binge drinking school areas (Table 5). One in five (18.6\%) respondents in highbinge drinking school sites reported at least one such secondhand effect, compared to only one in ten respondents in low-binge school areas.

\section{Role of alcohol outlets as mediating factor}

We conducted a path analysis to explore the degree to which alcohol outlets mediate the relationship between college factors (distance from college and college binge drinking levels) and the secondhand effects (Fig. 1). The Chi-square statistic was not significant and the CFI, NNFI, and NFI all exceeded 0.98 , indicating the model fits the observed data well. All path coefficients shown were significant at $p<0.05$. Distance from the closest college and college binge drinking level had an indirect effect on rates of secondhand problems through the number of alcohol outlets in the area. No direct effect of distance from a college on secondhand problems was found. Socioeconomic status had both direct and indirect effects on secondhand problems. The indirect or mediated effects of college, student drinking, and socioeconomic status on secondhand problems is stronger than direct effects, indicating that the presence of alcohol outlets appears to be essential for colleges and their binge drinking students to have a significant effect on neighborhood disruption.

\section{Discussion}

A survey of a national sample of households revealed significant correlations between the distance from the nearest college and such secondhand effects of heavy 
Table 4

Reported secondhand effects of alcohol by distance of respondent's home from college

\begin{tabular}{|c|c|c|c|c|}
\hline & \multirow{2}{*}{$\begin{array}{l}\text { More than } 1 \text { mile }^{\mathrm{a}}(n=1692) \\
(\%) 0\end{array}$} & \multicolumn{3}{|c|}{ Within a mile ${ }^{\mathrm{a}}(n=526)$} \\
\hline & & $(\%)$ & ORs & $(\mathrm{CI})^{\mathrm{b}}$ \\
\hline \multicolumn{5}{|l|}{ Secondhand effects ${ }^{\mathrm{c}}$} \\
\hline Litter & 72.8 & 79.3 & 1.22 & $(0.76-2.00)$ \\
\hline Noise or disturbance & 53.4 & 70.8 & 1.72 & $(1.10-2.70)^{*}$ \\
\hline Vandalism & 31.7 & 48.7 & 2.00 & $(1.27-3.23)^{* * *}$ \\
\hline People who are drunk & 35.6 & 58.5 & 2.00 & $(1.22-3.33)^{* *}$ \\
\hline Fighting or assault to others & 17.8 & 28.5 & 1.41 & $(0.85-2.38)$ \\
\hline Vomit or urination & 10.5 & 32.2 & 2.70 & $(1.54-4.76)^{* * *}$ \\
\hline Automobile accident or others & 40.2 & 46.1 & 1.19 & $(0.78-1.79)$ \\
\hline Four or more problems observed & 30.8 & 53.2 & 2.00 & $(1.25-3.23)^{* * *}$ \\
\hline \multicolumn{5}{|c|}{ College student-attributed secondhand effects ${ }^{\mathrm{d}}$} \\
\hline Litter & 5.2 & 11.9 & 2.27 & $(1.09-4.76)^{*}$ \\
\hline Noise or disturbance & 6.0 & 11.8 & 2.63 & $(1.20-5.88)^{*}$ \\
\hline Vandalism & 1.7 & 8.9 & 5.00 & $(1.39-16.67)^{* *}$ \\
\hline People who are drunk & 4.3 & 12.5 & 2.94 & $(1.19-7.14)^{*}$ \\
\hline Fighting or assault to others & 4.9 & 12.2 & 3.45 & $(0.81-14.29)$ \\
\hline Vomit or urination & 5.1 & 13.8 & 3.23 & $(075-14.29)$ \\
\hline Automobile accident or others & 3.2 & 5.4 & 2.27 & $(0.54-10.00)$ \\
\hline Any one of above problems & 8.3 & 19.5 & 2.78 & $(1.54-50.00)^{* * *}$ \\
\hline
\end{tabular}

${ }^{a}$ Respondent's estimate of distance of home from college.

${ }^{\mathrm{b}} \mathrm{ORs}$ are adjusted for $\%$ income, $\%$ race, and $\%$ owner occupied. OR $=$ odds ratio. $95 \% \mathrm{CI}=95 \%$ confidence interval.

$\mathrm{c}_{\%} \%$ reporting observing event one or more times.

$\mathrm{d}_{\%}$ who observed event and attributed it to college students.

$* p<0.05 ; * * p<0.01 ; * * * p<0.001 ; n=$ valid sample size.

Table 5

Secondhand effects attributed to college students by respondents near high and low binge level colleges

\begin{tabular}{|c|c|c|c|c|}
\hline & \multirow{2}{*}{$\begin{array}{l}\text { Low binge drinking school site }(n=817) \\
(\%)\end{array}$} & \multicolumn{3}{|c|}{ High binge drinking school site $(n=490)$} \\
\hline & & $(\%)$ & Adju & ORs $(95 \% \mathrm{CI})^{\mathrm{a}}$ \\
\hline \multicolumn{5}{|c|}{ College student-attributed secondhand effects ${ }^{\mathrm{b}}$} \\
\hline Litter & 4.7 & 15.8 & 3.36 & $(1.77-6.40)^{* * *}$ \\
\hline Noise or disturbance & 8.3 & 13.9 & 1.97 & $(1.12-3.44)^{*}$ \\
\hline Vandalism & 2.8 & 7.4 & 2.70 & $(0.76-9.68)$ \\
\hline People who are drunk & 7.9 & 15.8 & 2.32 & $(0.98-5.83)$ \\
\hline Fighting or assault to others & 4.0 & 5.8 & 1.60 & $(0.40-6.34)$ \\
\hline Vomit or urination & 1.1 & 8.7 & 3.93 & $(0.85-18.10)$ \\
\hline Automobile accident or others & 2.5 & 2.4 & 1.05 & $(0.32-3.44)$ \\
\hline Any one of above problems & 10.3 & 18.6 & 2.11 & $(1.21-3.68)^{* *}$ \\
\hline
\end{tabular}

${ }^{\mathrm{a}} \mathrm{ORs}$ are adjusted for $\%$ income, $\%$ race, and $\%$ owner occupied. $\mathrm{OR}=$ odds ratio. $95 \% \mathrm{CI}=95 \%$ confidence interval.

b $\%$ who observed event and attributed it to college students.

$* p<0.05 ; * * p<0.01 ; * * *<0.001 ; n=$ valid sample size.

alcohol use as noise, litter, and vandalism. Respondents residing near a college were at higher risk of experiencing such secondhand effects. They were also more likely to have alcohol outlets located near them. Path analysis indicated that residing near a college does not appear to be sufficient for experiencing high rates of secondhand problems. The colleges' contribution to neighborhood problems appears to operate through the presence of alcohol outlets. Our findings suggest that alcohol outlets are more often located in areas near colleges, particularly those with high rates of binge drinking. Community residents in these areas are likely to experience higher rates of neighborhood disruption. Such an interpretation is consistent with the literature on alcohol 


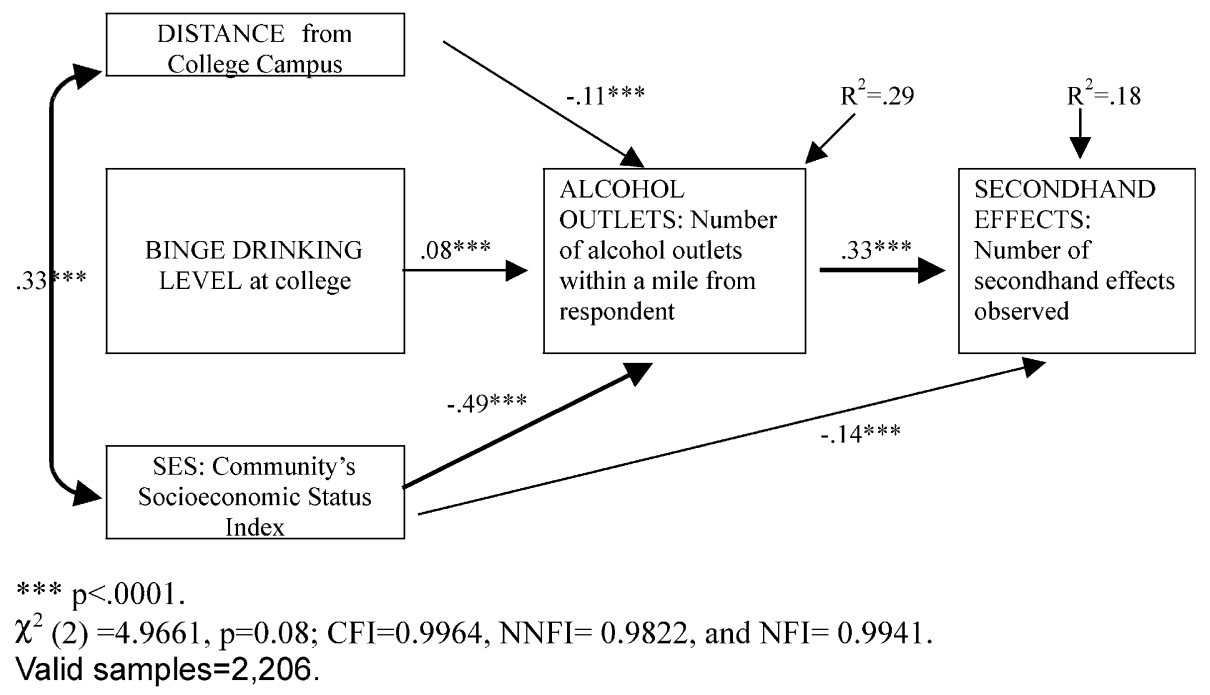

Fig. 1. Reduced path model of secondhand effects.

outlet density in general, which finds that higher outlet densities increase perceived availability of alcohol, lower retail price through increased competition, lower total cost to the drinker (including travel time), increases consumption of alcohol, and increases violence and other crime and disruption associated with drinking (Abbey et al., 1990; Alaniz et al., 1998; Scribner, Cohen, \& Fisher, 2000; Berman et al, 2000). Given the crosssectional design of the current study, we cannot answer the question of which came first. Does the presence of a college, especially with a high rate of heavy drinking, encourage more alcohol outlets? Or does the presence of many competing alcohol outlets encourage high rates of heavy drinking by the students of the nearby college? Our results suggest however, that rates of neighborhood disruption around colleges may be significantly reduced by limiting the presence of alcohol outlets in those areas.

Other factors contribute to the presence of alcohol outlets around many colleges. Our results indicate neighborhoods near colleges are more likely to be lower socioeconomic areas. These conditions might increase the ease of obtaining alcohol licenses, and produce a higher presence of outlets. Others have reported particularly high rates of alcohol outlet density in poor urban areas (Gorman \& Speer, 1997; LaVeist \& Wallace, 2000), and residents of these neighborhoods are more likely to report a range of social problems such as homelessness, crime, public drunkenness and loitering.

Current attempts to change student behavior through education and brief motivational techniques are among the main interventions colleges are using to reduce heavy drinking. Results of this study suggest that dealing with the high density of alcohol outlets and the marketing practices this engenders in neighborhoods immediately surrounding campuses may also be an important strategy. Strictly limiting licenses for new outlets and phasing out licenses of establishments that repeatedly violate serving and marketing regulations are means to reducing alcohol outlets. In many communities, half of all alcohol outlets regularly violate laws against selling or serving alcohol to those under the legal drinking age (Forster, Murray, Wolfson, \& Wagenaar, 1995), and a recent study revealed three-quarters of outlets violate laws prohibiting sales to patrons who already show signs of obvious intoxication (Toomey et al., 1999). Active enforcement of these laws is needed through regular compliance checks of all alcohol outlets, especially in college areas where sales to minors and sales to intoxicated infractions may be particularly prevalent. Such enforcement has immediate benefits in reducing risky sales practices (Jeffs \& Saunders, 1983; Preusser, Williams, \& Weinstein, 1994), and may have further benefits via the revocation of the licensees of particularly problem-prone outlets, and a gradual reduction in alcohol outlets in college neighborhoods. Residents who suffer the secondhand effects of heavy drinking can be enlisted in this effort, using a type of "neighborhood watch' operation. Raising licensing fees and alcohol taxes to pay for the prevention and cleanup of neighborhood disruption should be considered, especially since substantial majorities of the US general population support such policies (Wagenaar, Harwood, Toomey, Denk, \& Zander, 2000).

Another noteworthy finding suggests that lower socioeconomic conditions around college campuses 
may contribute to the presence of alcohol outlets. Disadvantaged neighbors may be less able to prevent the granting of licenses to sell alcohol. This may be part of a vicious circle: lower socioeconomic status near colleges may result in more alcohol outlets, more alcohol outlets may lead to more secondhand effects, and more secondhand effects may contribute to decreased real estate values and still lower SES. Efforts should be focused on how to disconnect the vicious circle.

A few cautions are important to consider when interpreting data from this study. The results are based on a telephone survey, and are subject to the limitations inherent in such methods. Persons without telephones cannot be part of the sample. However, in a large scale general population survey with adequate coverage and response rate the results for those who have phones were found to not differ significantly from those of the population as a whole (Aday, 1989). Sample attrition also occurs because of failure to obtain and complete interviews with the selected telephone numbers. The response rate of $50 \%$ may have introduced sampling bias. However, a comparison of selected demographic characteristics of the respondents with US census data indicated no significant differences. While other sources of bias may exist, the sample of respondents matches the characteristics of the general population.

In addition to possible sampling bias, self-reports may introduce a whole set of measurement error components (Del Boca \& Noll, 2000). However, such errors are likely to be random, and should not alter the nature of the relationships. Since we examined relationships at the aggregate or neighborhood level, estimates of a college's heavy drinking rate or a neighborhood's alcohol outlets and level of alcohol-related disruption represent an average for overall respondents at that site, by which the potential measurement errors may be averaged out.

In our study, distance from the nearest college, and number of alcohol outlets within a mile of home were based on respondents' estimates rather than physical measures, and may not exactly reflect real distances and actual number of outlets. However, using an administrator survey developed to obtain information on campus alcohol policies from deans of students or other administrators, Wechsler, Lee, Kuo and Lee (2000c) also found a statistically significant association of campus drinking levels with administrators' report of alcohol outlets located within a mile of their college. These consistent results using reports of distance from nearest alcohol outlet obtained from two different types of respondents serve to validate the measure. Furthermore, while not reflecting actual miles, respondents may be reporting the number of alcohol outlets within the area that they perceived as "their neighborhood".

One possible source of error that may not be random, relates to the drinking behavior of respondents. It is possible that respondents who drank more frequently were more aware of the outlets in their environment, and could provide more accurate, and probably fuller counts of them. Although we included questions about respondents' drinking behavior, we could not control for this factor because of the large number of no answers to this question $(45 \%)$. Since most analyses were conducted with dichotomous variables (no outlet vs. some outlets), the potential confounding effect of this factor may be minimized, though not fully discounted.

Another limitation in interpreting the results of the study is the cross-sectional design. While complex and expensive, future studies are needed to examine the role of alcohol outlets in heavy drinking on college campuses which track changes over time in both drinking rates and the density and practices of alcohol outlets. The best opportunities for such studies are most likely situations in which there are major changes in law, regulation or economic conditions that result in substantial changes in alcohol outlets over a relatively short period of time. Controlled time-series studies (Biglan, Ary, \& Wagenaar, 2000) of such natural experiments in select college communities may help further our understanding of the apparently important role alcohol outlets play in encouraging heavy drinking on college campuses.

\section{Acknowledgements}

We gratefully acknowledge the assistance of Elissa R. Weitzman in the development of the survey questionnaire. This study was supported by the Robert Wood Johnson Foundation.

\section{References}

Abbey, A., Scott, R. O., Olinsky, D. M., Quinn, B., \& Andreski, P. M. (1990). Subjective, social, and physical availability. II. Their simultaneous effects on alcohol consumption. International Journal of Addiction, 25(9), 1011-1023.

Abbey, A., Scott, R. O., \& Smith, M. J. (1993). Physical, subjective, and social availability: Their relationship to alcohol consumption in rural and urban areas. Addiction, $88(4), 489-499$.

Aday, L. A. (1989). Designing and conducting health surveys. San Francisco, CA: Jossey-Bass Inc..

Alaniz, M. L. (2000). Community-identified alcohol issues in the Mexican American community: Research design and utilization. Substance Use and Misuse, 35(1-2), 157-169.

Alaniz, L. A., Cartmill, R. S., \& Parker, R. N. (1998). Immigrant and violence: The importance of neighborhood context. Hispanic Journal of Behavioral Sciences, 20(2), 155174.

Alaniz, M. L., Parker, R. N., Gallegos, A., \& Cartmill, R. S. (1996). Alcohol outlet density and Mexican American youth violence. Final Progress Report, Inter-University Program for Latino Research, The Ford Foundation. 
Altman, D. G., Schooler, C., \& Basil, M. D. (1991). Alcohol and cigarette advertising on billboards. Health Education Research: Theory and Practice, 6(4), 487-490.

Bentler, P. M., \& Bonett, D. G. (1980). Significance test and goodness-of-fit in the analysis of covariance structures. Psychological Bulletin, 88, 588-606.

Berman, M., Hull, T., \& May, P. (2000). Alcohol control and injury death in Alaska native communities: Wet, damp and dry under Alaska's local option law. Journal of Student Alcoholism, 61(2), 311-319.

Biglan, T., Ary, D., \& Wagenaar, A. C. (2000). The value of interrupted time series experiments for community intervention and policy research. Prevention Science, 1(1), 31-49.

Brick, J. M., Waksberg, J., Culp, D., \& Starer, A. (1995). Bias in list-assisted telephone samples. Public Opinion Quarterly, 59, 218-235.

Bureau of the Census. (2000). Projections of The voting age population for November, 1998. Report P25, 1132, Government Printing Office.

Chaloupka, F. J., Grossman, M., \& Saffer, H. (1998). The effects of price on the consequences of alcohol use and abuse. Recent Developments in Alcoholism, 14, 331-346.

Chiu, A. Y., Perez, P. E., \& Parker, R. N. (1997). Impact of banning alcohol on outpatient visits in Barrow, Alaska. Journal of the American Medical Association, 278(21), 17751777.

Coate, D., \& Grossman, M. (1988). Effects of alcohol beverage prices and legal dinking ages on youth alcohol use. Journal of Student Alcoholism, 48, 167-175.

Del Boca, F. K, \& Noll, J. A. (2000). Truth or consequences: The validity of self-report data in health services research on addictions. Addiction, 95(Suppl 3), S347-S360.

Edwards, G., Anderson, P., Babor, T. F., Casswell, S., Ferrence, R., \& Giesbrecht, N., et al. (1995). Alcohol policy and the public good (pp. 125-152). New York: Oxford University Press.

Forster, J. L., Murray, D. M., Wolfson, M., \& Wagenaar, A. C. (1995). Commercial availability of alcohol to young people: Results of alcohol purchase attempts. Preventive Medicine, 24, 342-347.

Fox, J. G., \& Sobol, J. J. (2000). Drinking patterns, social interaction, and barroom behavior: A routine activities approach. Deviant Behavior, 21(5), 429-450.

Frankel, L. R. (1983). The Report of the CASRO Task Force on Response Rates. In F. Wiseman (Ed.), Improving data quality in a sample survey. Cambridge, MA: Marketing Science Institute.

Gorman, D. M., Labouvie, E. W., Speer, P. W., \& Subaiya, A. P. (1998a). Alcohol availability and domestic violence. American Journal of Drug Alcohol Abuse, 24(4), 661-673.

Gorman, D. M., \& Speer, P. W. (1997). Concentration of liquor outlets in an economically disadvantaged city in the Northeastern United States. Substance Use and Misuse, 32(14), 2033-2046.

Gorman, D. M., Speer, P. W., Labouvie, E. W., \& Subaiya, A. P. (1998b). Risk of aussaltive violence and alcohol availability in New Jersey. American Journal of Public Health, 88 , 97-100.

Gorsky, R. D., Schwartz, E., \& Dennis, D. (1988). The mortaility, morbidity, and economic costs of alcohol abuse in New Hampshire. Preventive Medicine, 17(6), 736-745.
Gruenewald, P. J., Madden, P., \& Janes, K. (1992). Alcohol availability and formal power and resources of state alcohol beverage control agencies. Alcoholism: Clinical \& Experimental Research, 16(3), 591-597.

Gruenewald, P. J., Miller, A. B., \& Treno, A. J. (1993). Alcohol availability and the ecology of drinking behavior. Alcohol Health and Research World, 17(1), 39-45.

Gruenewald, P. J., Treno, A. J., Nephew, T. M., \& Ponicki, W. R. (1995). Routine activities and alcohol use-constraints on outlet utilization. Alcoholism: Clinical \& Experimental Research, 19(1), 44-53.

Hackbarth, D. P., Silvestri, B., \& Cosper, W. (1995). Tobacco and alcohol billboards in 50 Chicago neighborhoods: Market segmentation to sell dangerous products to the poor. Journal of Public Health Policy, 16(2), 213-230.

Hatcher, L. (1994). A step-by-step approach to using the sas system for factor analysis and structural equation modeling. Cary, NC: SAS Research Institute Inc..

Jeffs, B. W., \& Saunders, W. M. (1983). Minimizing alcohol related offences by enforcement of the existing licensing legislation. British Journal of Addiction, 78, 67-77.

Jewell, R. T., \& Brown, R. W. (1995). Alcohol availability and alcohol-related motor vehicle accidents. Applied Economics, 27, 759-765.

Jones-Webb, R., Toomey, T. L., Short, B., Murray, D. M., Wagenaar, A., \& Wolfson, M. (1997). Relationship among alcohol availability, drinking location, alcohol consumption, and drinking problems in adolescents. Substance Use and Misuse, 32(10), 1261-1285.

Keeter, S. (1995). Estimating noncoverage bias from a phone survey. Public Opinion Quarterly, 59, 196-216.

LaVeist, T. A., \& Wallace Jr., J. M. (2000). Health risk and inequitable distribution of liquor stores in African American neighborhood. Social Science and Medicine, 51(4), 613617.

Lepkowski, J. (1988). Telephone sampling methods in the United States. In Robert M. Groves, et al. (Ed.), Telephone survey methodology. New York: Wiley.

Mann, R. E., Smart, R. G., Anglin, L., \& Adlaf, E. M. (1991). Reductions in cirrhosis deaths in the United States: Associations with per capita consumption and AA membership. Journal of Student Alcoholism, 52(4), 361-00365.

Mustaine, E. E., \& Tewksbury, R. (1998). Predicting risks of larceny theft victimization - a routine activity analysis using refined lifestyle measures. Criminology, 36(4), 829-857.

O'Malley, P., \& Wagenaar, A. C. (1991). Effects of minimum drinking age laws on alcohol use, related behaviors, and traffic crash involvement among American youth 19761987. Journal of Student Alcoholism, 52, 478-491.

Parker, D. A., Wolz, M. W., \& Harford, T. C. (1978). The prevention of alcoholism: An empirical report on the effects of outlets availability. Alcoholism: Clinical \& Experimental Research, 2(4), 339-343.

Preusser, D. F., Williams, A. F., \& Weinstein, H. B. (1994). Policing underage alcohol sales. Journal of Safety Research, 25, 127-133.

Rabow, J., \& Watts, R. K. (1982). Alcohol availability, alcoholic beverage sales and alcohol-related problems. Journal of Student Alcoholism, 43(7), 767-801.

Rush, B., Steinberg, M., \& Brook, R. (1986). The relationships among alcohol availability, alcohol consumption and 
alcohol-related damage in the province of Ontario and the state of Michigan 1955-1982. Advances in Alcohol Substance Abuse, 5(4), 33-45.

Scribner, R. A., Cohen, D. A., \& Farley, T. A. (1998). A geographic relation between alcohol availability and gonorrhea rates. Sex Transmission Diseases, 25(10), 544-548.

Scribner, R. A., Cohen, D. A., \& Fisher, W. (2000). Evidence of a structural effect for alcohol outlet density: A multilevel analysis. Alcoholism: Clinical \& Experimental Research, 24(2), 188-195.

Scribner, R., Cohen, D., Kaplan, S., \& Allen, S. H. (1999). Alcohol availability and homicide in New Orleans: Conceptual considerations for small area analysis of the effect of alcohol outlet density. Journal of Student Alcoholism, 60(3), 310-316.

Scribner, R. A., MacKinnon, D. P., \& Dweyer, J. H. (1994). Alcohol outlet density and motor vehicle crashes in Los Angeles county cities. Journal of Student Alcoholism, 55, 447-453.

Scribner, R. A., MacKinnon, D. P., \& Dweyer, J. H. (1995). The risk of assaultive violence and alcohol availability in Los Angeles County. American Journal of Public Health, 85(3), 335-340.

Shah, B. V., Barnwell, B. G., \& Bieler, G. S. (1997). Sudaan user's manual, release 7.5. Research Triangle Park, NC: Research Triangle Institute.

Smart, R. G., Mann, R. E., \& Suurvali, H. (1998). Changes in liver cirrhosis death rates in different countries in relation to per capita alcohol consumption and alcoholics anonymous membership. Journal of Student Alcoholism, 59(3), 245-249.

Speer, P. W., Gorman, D. M., Labouvie, E. W., \& Ontkush, M. J. (1998). Violent crime and alcohol availability: Relationships in an urban community. Journal of Public Health Policy, 19(3), 303-318.

Tatlow, J. R., Clapp, J. D., \& Hohman, M. M. (2000). The relationship between the geographic density of alcohol outlets and alcohol-related hospital admissions in San Diego County. Journal of Community Health, 25(1), 79-88.

Toomey, T. L., Wagenaar, A. C., Kilian, G., Fitch, O., Rothstein, C., \& Fletcher, L. (1999). Alcohol sales to pseudo-intoxicated bar patrons. Public Health Reports, 114(4), 337-342.
Wagenaar, A. C. (1993). Minimum drinking age and alcohol availability to youth: Issues and research needs. Research Monograph 25, US Department of Health and Human Services, National Institute on Alcohol Abuse and Alcoholism, Rockville, MD.

Wagenaar, A. C., Harwood, E. M., Toomey, T. L., Denk, C. E., \& Zander, K. M. (2000). Public opinion on alcohol policies in the United States: Results from a national survey. Journal of Public Health Policy, 21(3), 303-327.

Wagenaar, A. C., Toomey, T. L., Murray, D. M., Short, B. J., Wolfson, M., \& Jones-Webb, R. (1996). Sources of alcohol for underage drinkers. Journal of Student Alcoholism, 57, 325-333.

Wechsler, H., Davenport, A., Dowdall, G., Moeykens, B., \& Castillo, S. (1994). Health and behavioral consequences of binge drinking in college: A national survey of students at 140 campuses. Journal of the American Medical Association, 272, 1672-1677.

Wechsler, H., Dowdall, G. W., Davenport, A., \& Castillo, S. (1995a). Correlates of college student binge drinking. American Journal of Public Health, 85, 921-926.

Wechsler, H., Dowdall, G. W., Maenner, G., Gledhill-Hoyt, J., \& Lee, H. (1998). Changes in binge drinking and related problems among American college students between 1993 and 1997. Journal of the American College of Health, 47, 5768.

Wechsler, H., Kelly, K., Weitzman, E. R., Giovanni, J. P., \& Seibring, M. (2000a). What colleges are doing about student binge drinking. A survey of college administrators. Journal of the American College of Health, 48, 219-226.

Wechsler, H., Kuo, M., Lee, H., \& Dowdall, G. W. (2000b). Environmental correlates of underage alcohol use and related problems of college students. American Journal of Preventive Medicine, 19(1), 24-29.

Wechsler, H., Lee, J. E., Kuo, M., \& Lee, H. (2000c). College binge drinking in the 1990s: A continuing problem results of the Harvard school of public health 1999 college alcohol study. Journal of the American College of Health, 48, 199210 .

Wechsler, H., Moeykens, B., Davenport, A., Castillo, S., \& Hansen, J. (1995b). The adverse impact of heavy episodic drinkers on other college students. Journal of Student Alcoholism, 56, 628-634. 